\title{
Shiftwise Production Estimation of Asbestos Sheets using General Industrial Controls (GIC)
}

\author{
R. Rajkumar, V. Asmitha, R. Bharath Kumar, R. Bharathidhasan, G. Keerthana
}

\begin{abstract}
A rooftop is a top covering of a structure, including all materials and developments important to help it on the dividers of the structure and also provides protection against rain, wind, snow, sunlight and excess of temperature. The asbestos sheet is used in the 20th century widely because of inexpensive and non-flammable properties. South America and Asia are using asbestos in the vital range for producing asbestos cement sheets where the other continents stopped using because of health and legal issues during mining and handling of asbestos. Many industries are involved in the production of asbestos sheets. In such industries, counting of sheets is done by using a proximity sensor during the piling of sheets per day consecutively. The count per hour and count per shift are the manual jobs done by workers. The worker needs to count the sheets manually every hour and should record the count in the register books. Manual works may lead to errors and also it took much time for counting and recounting sheets if there is some error in counting. Hence an automatic counting per hour and per shift method is proposed in this paper. Normally, proximity sensor is used to count sheets. In addition to that GIC PL100 (PLC) is used for counting the sheets per hour and shift and SCADA is for displaying the sheet count in Personal Computer. This proposed method completely avoids the manual intervention and gives an accurate count by proximity senor.
\end{abstract}

Keywords: asbestos sheets, counting, GIC PL100, Modbus address, piling, SCADA.

\section{INTRODUCTION}

Roofing asbestos cement sheets play a major role in the industrial and farmyard buildings. Figure 1 shows the asbestos cement sheet. The word asbestos is first used in the 1600s which derives from the Ancient Greek meaning "unquenchable" or "inextinguishable" [1]. Asbestos was first used in the yarn manufacturing, and Louis Wertheim, a German industrialist adopted this process in his factories in Germany [2]. About 33 large - scale asbestos manufacturing plants and 673 small-scale asbestos mining and milling facilities are situated in India [3]. Asbestos sheet and roofing made of various sizes, colors and also in different quality from lower to the higher cost to meet the needs of all class people.

\section{Revised Manuscript Received on April 25, 2020.}

* Correspondence Author

V. Asmitha*, Department of Electronics and Instrumentation Engineering, Kongu Engineering College, Perundurai, Tamil Nadu, India.

R. Rajkumar, Assistant Professor, Department of Electronics and Instrumentation Engineering, Kongu Engineering College, Perundurai, Tamil Nadu, India.

R. Bharath Kumar, Department of Electronics and Instrumentation Engineering, Kongu Engineering College, Perundurai, Tamil Nadu, India.

R. Bharathidhasan, Department of Electronics and Instrumentation Engineering, Kongu Engineering College, Perundurai, Tamil Nadu, India.

G. Keerthana, Department of Electronics and Instrumentation Engineering, Kongu Engineering College, Perundurai, Tamil Nadu, India.

(C) The Authors. Published by Blue Eyes Intelligence Engineering and Sciences Publication (BEIESP). This is an open access article under the CC BY-NC-ND license (http://creativecommons.org/licenses/by-nc$\underline{\operatorname{nd} / 4.0 /)}$
The industries are running $24 * 7$ with various sections like production, power generation, maintenance, service, and marketing with their required engineers for specified departments. Asbestos cement sheet is a thin arduous cement sheet. It is made from the mixture of asbestos chrysotile fibre, scrap, cement powder, cement substitute, cotton rack pulp, and wooden scrap. The Zetex texture is lighter than asbestos yet offers a similar mass, thickness, hand, feel, and scraped area opposition as asbestos.

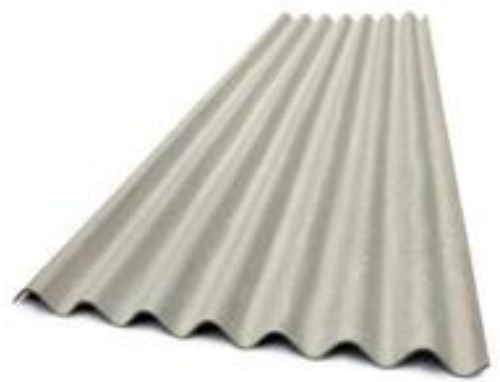

Fig. 1. Asbestos cement sheet

The current or historical commercial usefulness due to their extraordinary tensile strength, poor heat conduction and relative resistance to chemical attack [4]. This mixture is usually formed into a flat wet sheet and then molded into a particular shape. Introduction to asbestos, including chrysotile, causes disease of the lung, larynx and ovary, mesothelioma (a malignancy of the pleural and peritoneal linings) and asbestosis (fibrosis of the lungs) [5]. In this mixture asbestos chrysotile, fibre and cement powder are the main products, so it deserves a name called asbestos cement sheet. There are totally three mixers named fibre mixer, cement mixer and pulp mixer in the plant. The materials from those three mixers are fed into the main mixer called agitator tank. The felt is similar to the conveyor belt of $28 \mathrm{~m}$ which is used in the plant. The final material from the agitator tank is moving on the felt. There is 6 VAT in the felt which makes the flat wet cement sheet with a moisture content of $30 \%$. Piling is a process of molding the flat wet sheet into the particular shapes and suction of that wet sheet to move from one place to another. After piling the molded sheets are sent to the heating chamber. Sheets are heated at a 45 degree Celsius for 8 to 9 hours to produce dry rigid asbestos sheets. After the heating process, the de-piling process takes place from which the damaged sheets were found. Perfect sheets are stored in the stockyard for 21 days before despatch. For counting the sheets, the proximity sensor is placed in the piling machine so that it counts during each piling. This counter shows the total of one-day counting and never resets until it is done manually. So the production of sheets per hour and per shift (8 hours) is very hard to calculate. Counting sheets per hour and per shift is still the manual work in the plant.

Published By:

Blue Eyes Intelligence Engineering DOI: 10.35940/ijeat.D7528.049420

Journal Website: www.ijeat.org

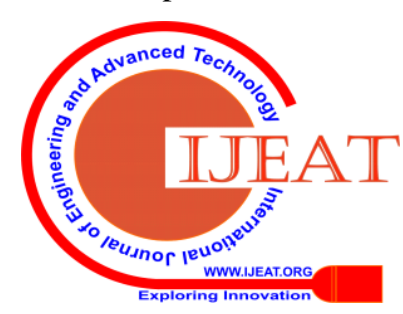

\& Sciences Publication

1089 (C) Copyright: All rights reserved. 
To reduce the manual work and avoid the error in counting, the shift wise and hour wise counting of asbestos sheets using GIC PL-100 is proposed. PLCs were customized utilizing exclusive programming boards or unique reason programming terminals, which regularly had committed capacity keys speaking to the different sensible components of PLC programs [6]. Remote terminal units, otherwise called (RTUs) [7], associate with sensors and actuators all the while and are organized to the supervisory PC framework. The overall process is connected to SCADA and controlled by it. PLC was created with a few favourable circumstances over prior plans. It would endure the modern condition, be effectively extensible with extra I/O (take into consideration simpler reconfiguration and cycle over assembling process configuration), be moderately easy to utilize, and would allow its activity to be checked [8]. PLC would permit its operation to be monitored [8]. This counts the sheet production and stored in the particular counter Modbus address i.e., from 300739 to 300766 . The counting of asbestos sheets per hour and per shift are displayed by using SCADA in PC. Modern carrier-class systems provide the service quality required for SCADA [9].

\section{LITERATURE REVIEW}

\section{A. Existing method}

In Everest Industries limited, the produced sheets were counted by proximity sensor during piling consecutively per day. There is no suitable counter for shift wise sheet counting as well as for hourwise

sheet counting. The counting of manufactured sheets per hour and per shift is manual work. Shift wise and hour wise counting of sheets were registered at the end of the shift by the supervisor. A register book is maintaining in the industry for production count and future purposes. There are many problems due to manual job.

\section{B. Observation}

The following points were observed through the literature carried out,

$\square$ Manual counting requires man power and leads to incorrect estimation.

$\square \quad$ Recounting and inaccuracy in production occurs many time.

$\square \quad$ Missing of register book leads to many difficulties and issues.

Shiftwise counting is required.

Data storage and retrieval for future usage is difficult.

\section{Proposed method}

GIC PL100 is used to count manufactured sheets in the proposed method. The Counting per hour and per shift is normally done by proximity sensor with GIC PL100, so the hour wise count and shift wise count are automatically calculated and stored in the retentive up/down counter Modbus address. The counted value must be stored in a counter address i.e., from 30739 to 30765 . The count for each hour and each shift is stored in the different addresses. After every 24 hours, the data is stored and all values are reset to ZERO for next count.

\section{SYSTEM DESCRIPTION}

The major functional block diagram of the proposed method is shown in Figure 2. This includes GIC PL100, Switched Mode Power Supply (SMPS), USB to serial converter, USB to serial converter driver, proximity sensor and ON/OFF switch. The software used in this project is PL-Soft PLC, WinTr SCADA.

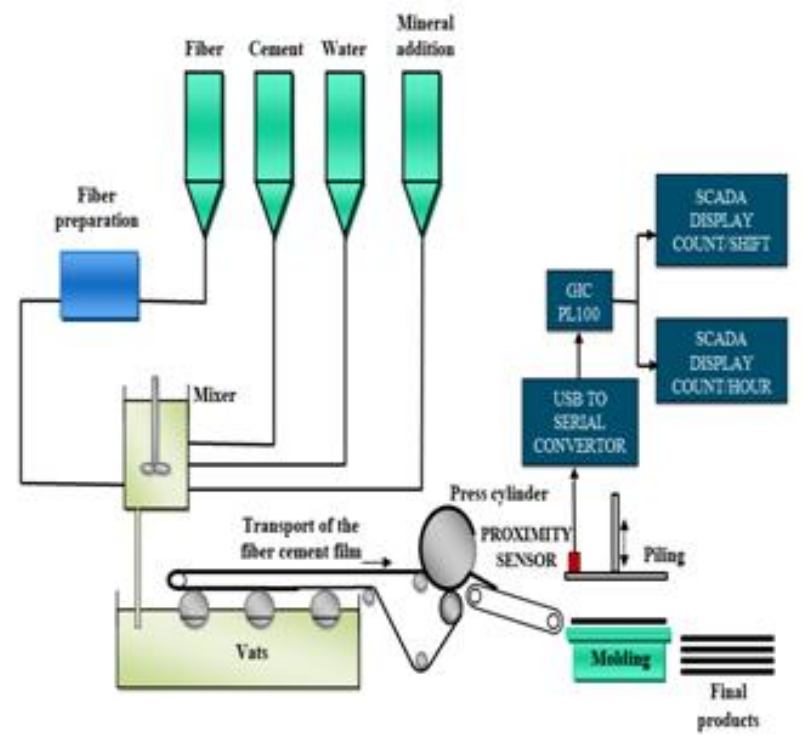

Fig. 2.Block Diagram

GIC PL100 is a mini PLC controller that is used in many industries to monitor inputs and outputs depending upon their states. PLCs were customized utilizing exclusive programming boards or unique reason programming terminals, which regularly had committed capacity keys speaking to the different sensible components of PLC programs [10]. PLC makes decisions based on its program and automates a process by turning ON/OFF the device. This PLC supports up to 100 IOs. There is a rapid data sources $(1 \mathrm{x} / 2 \mathrm{x} / 4 \mathrm{x})$ and fast yields (PTO/PWM/S-Profile), Analog Voltage/Current Inputs and Outputs of 0-10 V/4-20 mA, Standard RS232/RS485 port with RJ11 for HMI/SCADA Interface, Mini PLC has support Modbus RTU. There are weekly, monthly and yearly time switches and many timers, counters including retentive counters, Hour meters, and many function blocks. It takes some time for the processor of the PLC to evaluate all the rungs and update the I/O image table with the status of outputs [11]. Switch mode power Supply (SMPS Switching Mode Power Supply) which provides the output Voltages generated in the AC-network-input Switch mode power supply [12] SMPS is a power supply unit (PSU) that is used to convert the voltage into computer acceptable range. Due to the presence of power handling components, this device gives efficient power. Switching-mode power supply, switching power supply, and switching regulator refer to this type of power supply [13]. The USB to serial converter includes RS-232/RS-485/RS-422. USB to serial converter converts the data send from the USB port to the serial data to the RS485/RS422 port. In USB to RS-485/422, the input is given through USB 2.0 Protocol and the output is given through RS232 on DB9 Male connector compatible to PC RS485/RS422 on the terminal block.

Published By:

Blue Eyes Intelligence Engineering \& Sciences Publication

DOI: 10.35940/ijeat.D7528.049420

Journal Website: www.ijeat.org

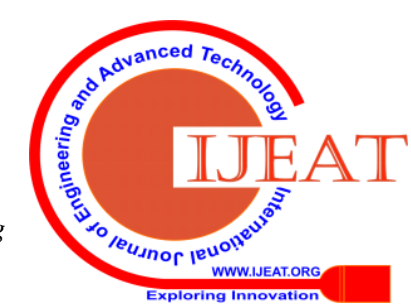


The Communication speed is from 300bps to 230Kbps. An LED indication is for both transmit and receive signals. It is unable to connect the USB to serial converter directly to the PC. The software is to be installed, so that the connection is happen by entering port number, serial number in the software. A proximity sensor is used to detect the presence of the object in an invasive method by emitting electromagnetic radiation. It has a sensing scope from 3 to $60 \mathrm{~mm}$.

Normally the ON/OFF switch is used to ON and OFF the total circuit. At present ladder logic remains the dominant language [14]. PL-Soft is used to create, simulate, and download the program from a PC to PL-100. PL-Soft also offers functions for simulating the control program, documenting the project and also for establishing communication between the PC and the PL-100. It is userfriendly, supports ladder program, easy simulation of a ladder and easy downloading and uploading of the ladder program. WinTr is one of the advanced software for SCADA programming. This is used for monitoring and saving data of the manufacturing process which separated large areas. Devices are managed from the single station. The device can be connected with OPC Client, S7 MPI, Profinet (S7 1200), Host-Link protocolsS7 PPI, Modbus RTU, Modbus TCP/IP. Historical data related to processes are saved into the database. WinTr Client has no count limitation for connecting to the WinTr Server. At a time, WinTr Client can connect up to 1000 WinTr Server. WinTr can be configured to sending SMS and E-Mail when the previously specified event occurred. Control Panel has the print page configuration section. Page can be saved as an image or sent to a printer for a hard copy. Control Panel has a report manager section and it is used for creating reports from historical Tag values according to Date. It creates easy detailed reports from past data and saves them in Excel or PDF format. Control Panel has a web server module section that is used for displaying WinTr Screens remotely by using Web Browsers such as Internet Explorer, Firefox, etc. Then by typing http://IP_Address:Port_Number to the browser's address bar the SCADA screens can be accessed from any computer that has an internet connection. Web SCADA frameworks use web programs, for example, Google Chrome and Mozilla Firefox as the graphical UI (GUI) for the administrators HMI [15]-[16]. SMPS (-ve) is connected to the GIC PL100 (-ve), SMPS (+ve) is connected to ON/OFF switch (4). ON/OFF switch (3) is connected to the GIC PL100 (+ve). Proximity sensor black and blue wires are connected to GIC PL100 (+ve) and brown wire us connected to Input 1 of GIC PL100. USB to serial converter is connected to the GIC PL100 for data sharing. The controller of the total process is the ON/OFF switch. The process works only when the switch is in the ON condition. A proximity sensor is fixed to the piling machine. The counter starts counting only when the proximity sensor senses i.e., during piling. The program for sheet counting per hour and per shift is done by using PLsoft software and dumped into GIC PL100. The display screen for the counter value is developed by using WinTr SCADA software. The GIC PL100 is connected to the SCADA by using USB to the serial converter.

\section{DESIGN AND METHODOLOGY}

The circuit connections are given as per the figure 3 . The proposed method reduces the manual work by counting automatically per hour and per shift. For counting and displaying the count, PLC and SCADA program are done by using PL-soft software and WinTr SCADA software. Time switch describes the specified time period in which it enables the action need to takes place within the predefined time slot.

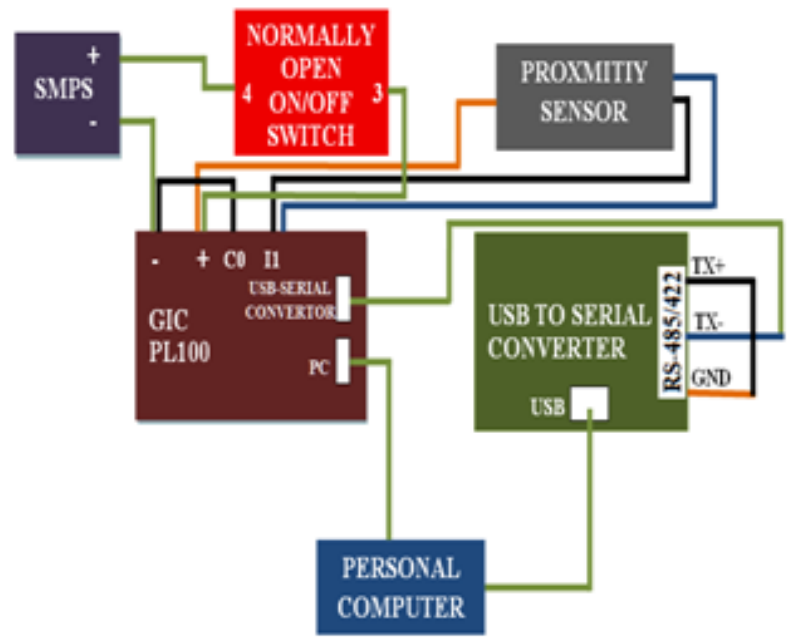

Fig. 3.Circuit Diagram

After that, it disables the action. It enables when time validation is true. There are totally 27 time switches used. In this, 24 time switches are describing the every one hour. These Other 3 time switches are used for representing 3 shifts i.e., shift $1-7 \mathrm{am}$ to $3 \mathrm{pm}$, shift $2-3 \mathrm{pm}$ to $11 \mathrm{pm}$ and shift 3-11pm to $7 \mathrm{am}$. These time switches should work for all the seven days in the week for a specific time slot. Retentive up/down counter is used to count the asbestos sheets. It may be used as both up or down counter. It counts as long as trigger input is $\mathrm{ON}$, but does not reset when the supply goes OFF. The counter modbus address is from 30739 to 30765 . The address from 30739 to 30741 stores the shift counts and address from 30741 to 30765 stores the hour counts. The reset of all the counted value is done by using ON delay timer. In SCADA programming the modbus counter address, tag name and value are to be stored in Modbus Rtu/Tcp Master which is located in connection manager as shown in figure 4 and figure 5 . Then screen need to be designed in screen designer as shown in the figure 6 . In this the tag name is to be assigned for the particular text box as shown in the figure 7. This connects the PLC with SCADA. In USB to serial converter USB port is connected with the PC for SCADA information sharing and displaying and from RS 485/422 port to GIC PL100. This converts the data obtained from USB to serial information and send it through the RS 485/422 port in USB to serial convertor to RS 485 port in GIC PL100. Other connections are given as per the connection which is discussed in the system description. Proximity sensor is fixed on the piling machine, so that it senses when the piling process takes place. This process increases the count by 1 in both the specific hour and specific shift counter. This value is stored in the particular modbus address according to the hour and shift.

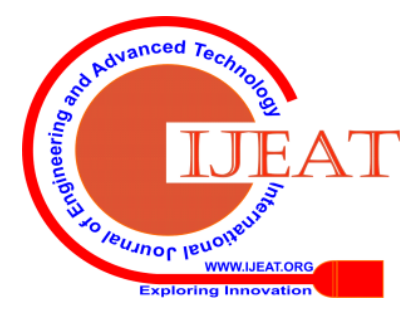




\section{Shiftwise Production Estimation of Asbestos Sheets using General Industrial Controls (GIC)}

Likewise the process should be repeated for all the hours, shifts and 7 days in the week. This data may shared with the other authorized person by SMS, E-mail, web browser in WinTr SCADA. The email address or telephone number is to be stored previously for getting the information. The report is also created from the historical data to check the current data in WinTr SCADA. The figure 8 shows the final display of screen while running.

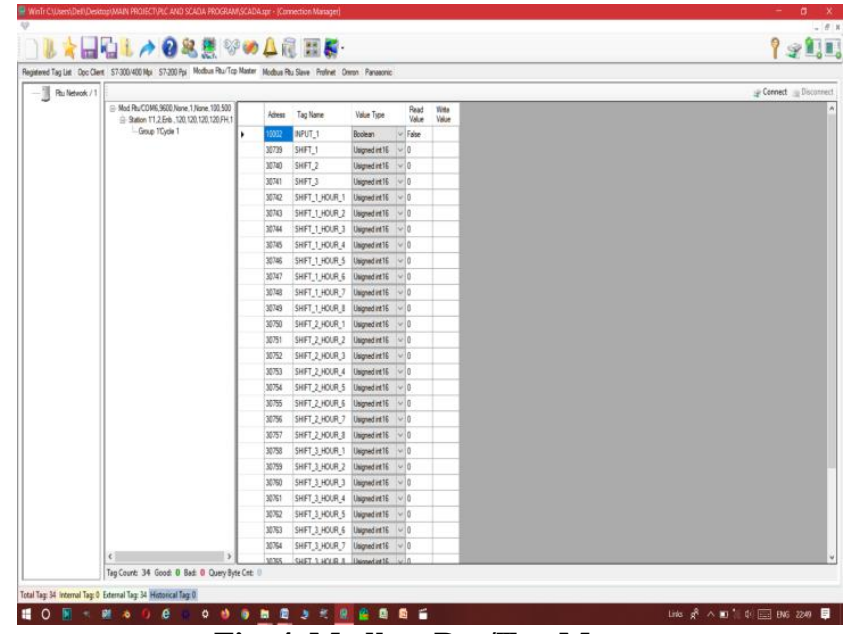

Fig. 4. Modbus Rtu/Tcp Master

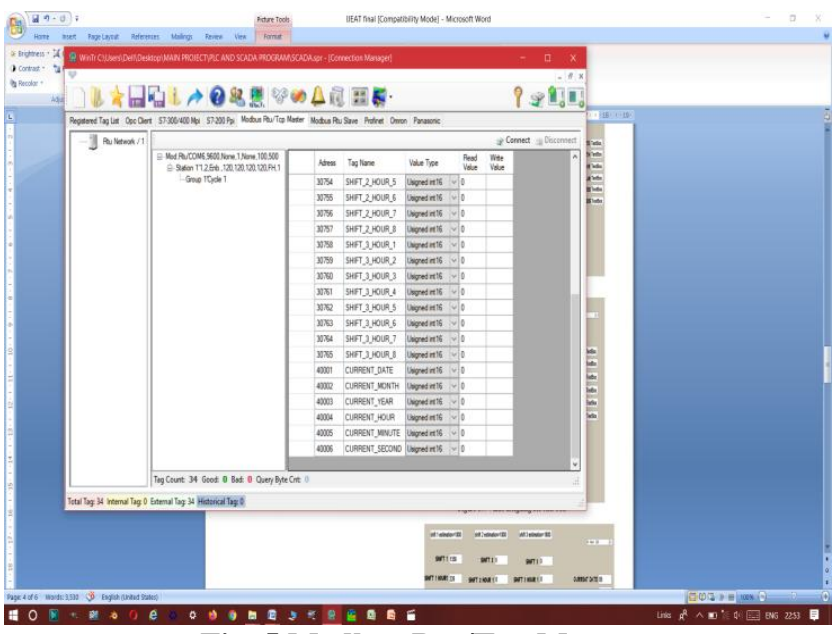

Fig. 5.Modbus Rtu/Tcp Master

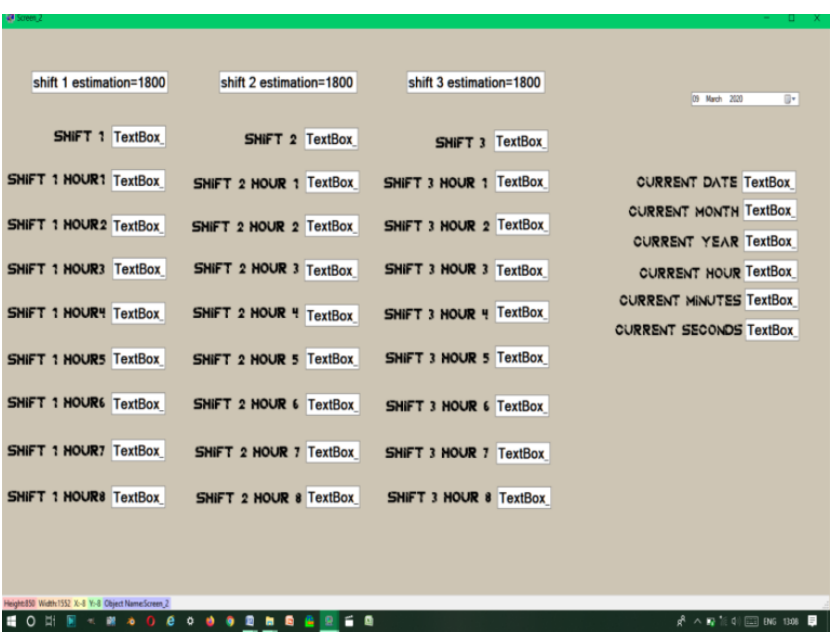

Fig. 6.Display Screen

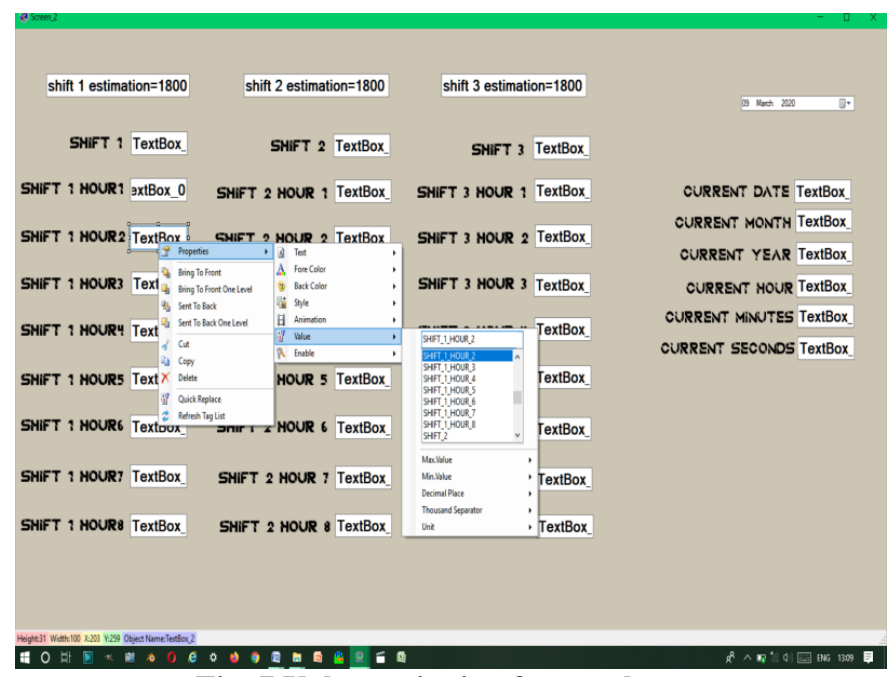

Fig. 7.Value assigning for text box

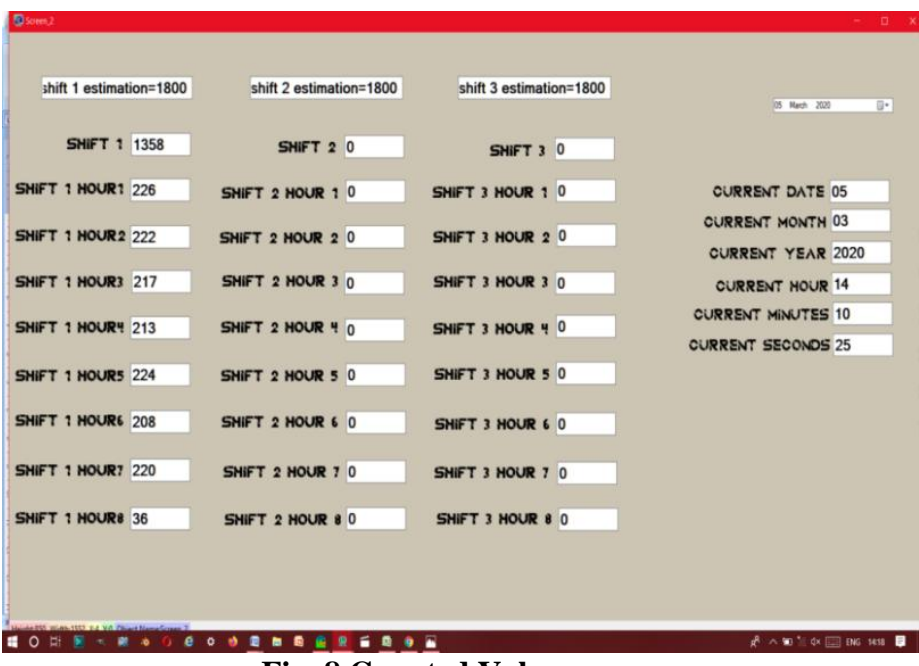

Fig. 8.Counted Values

\section{ADVANTAGES OF USING GIC}

1. It is designed to withstand vibration, electromagnetic Interference, humidity, temperature variation.

2. Easy to program and understand.

3. Flexibility: One single Programmable Logic Controller can easily run many machines.

4. Firmware update function ensures Users for the latest updates.

5. I/O flexibility is achieved through the wide variety of available digital and analog modules covering a range of voltage and current ratings.

\section{ADVANTAGES OF USING GIC}

1. No need for LED displays for displaying the counted value.

2. Page can be sent to printer or saved as an image.

3. Reports can be exported as PDF or Excel file. Representation of the chart can be added to the PDF report.

4. Screens can be accessed from any computer that has an internet connection by using the URL.

5. WinTr can be configured to sending SMS and E-Mail.

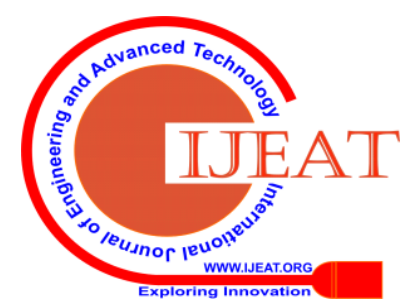




\section{RESULT AND DISCUSSION}

The ON delay timer is used in PLC program for reset purpose. Daily the new counting value starts at 7AM and ends at 6.59AM the next day. The 3600 seconds is the preset value in ON delay timer. Start counting of 3600 seconds when the timer enables. The ON delay timer enables when the time is 6AM and enables the reset when the timer reaches the preset value. After enabling reset all the counter values will be stored and resets to Zero for the next count. The result obtained from this project is displaying produced sheet count per hour and per shift in SCADA. This result may shared with the authorised person via SMS, e-mail and URL daily by pre-entering mail id, mobile/telephone number in WinTr SCADA. This comprehend each hour and each shift in a single sheet. So the observation and analogy are so transparent. Making PDF and report are very easy by take a look past records.

\section{CONCLUSION}

Approximately one sheet takes 16 seconds to reach the piling machine. So production of sheets per hour is 225 as per the estimation. Totally 5400 sheets are to be produced according to the estimation. The sheet count may changes according to machine errors, shutdowns or some other problems. This method easily shows the production difference between each hour and each shift. The final screen which shows the count per hour and per shift is shown in the figure 9. This type of counting shows easy differentiation between shifts and hours.

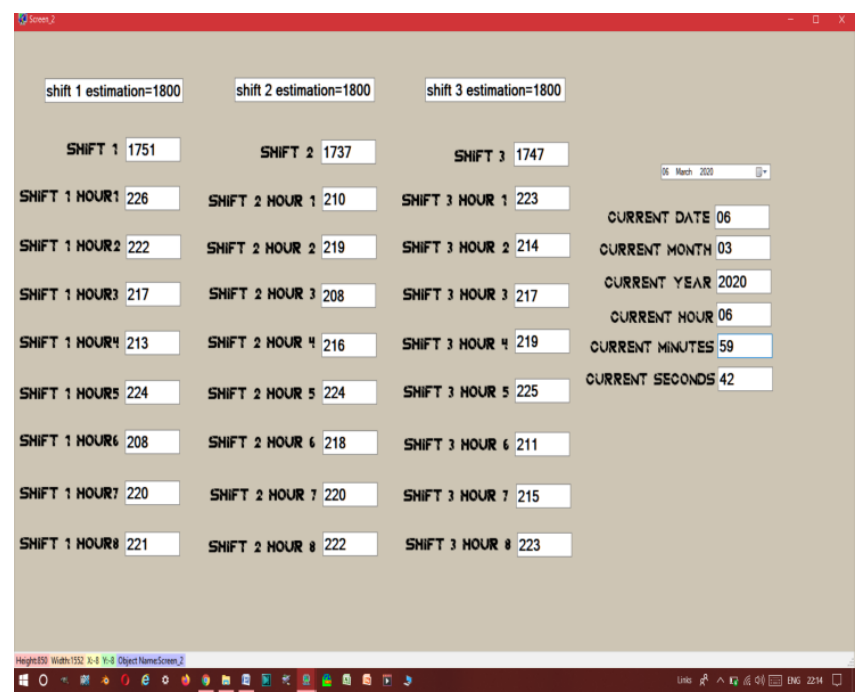

Fig. 9.Final result screen

The major advantage from this proposed method is showing difference between the estimation and production. This method reduces the manpower in counting the sheets and also gives report from the previous historical data for further improvement. This is so convenient for counting and storing the count rather than maintaining a register. This method is so cost effective for counting sheets $24 * 7$ and also increases the efficiency of the production and reduces the counting time.

\section{REFERENCES}

1. James E. Alleman, Brooke T. Mossman, "Asbestos Revisited"(PDF). Scientific American, July 1997, page: 54-57.

2. Irving J. Selikoff and Douglas H.K.Lee., "Asbestos and Disease". Elsevier. 1978, pp. 8-20. ISBN.

3. F. A. Ansari, V. Bihari, ${ }^{*}$ S. K. Rastogi, ${ }^{*}$ M. Ashquin, and I. Ahmad, "Environmental health survey in asbestos cement sheets manufacturing industry". IJOEM. Volume: 11, Issue: 1, 2007 JanApr, Page:15-20.

4. Concha-Barrientos M, Nelson D, Driscoll T, Steenland N, Punnett L, Fingerhut $\mathrm{M}$ et al. Chapter 21. Selected occupational risk factors. In: Ezzati M, Lopez A, Rodgers A, Murray C, editors. "Comparative quantification of health risks: global and regional burden of disease attributable to selected major risk factors." Geneva: World Health Organization, 11 March 2014.

5. Driscoll T, Nelson DI, Steenland K, Leigh J, Concha-Barrientos M, Fingerhut $\mathrm{M}$ et al, "The global burden of disease due to occupational carcinogens. Am J Ind Med. Volume: 1, 2005, Page: 1-15

6. M. A. Laughton, D. J. Warne (ed), "Electrical Engineer's Reference book", 16th edition, Newnes, 2003 Chapter 16 Programmable Controller

7. Jeff Hieb (2008). "Security Hardened Remote Terminal Units for SCADA Networks", University of Louisville, February 26, 2008

8. Parr, E.A., "Industrial Control Handbook", Industrial Press, 1999, Inc.pp.450-451.

9. Bergan, Christian (August 2011). "Demystifying Satellite for the Smart Grid: Four Common Misconceptions". Electric Light \& Powers. Utility Automation \& Engineering T\&D. Tulsa, OK: PennWell. 16 (8). Four. Archived from the original on 31 March 2012. Retrieved 2 May 2012.

10. Harms, Toni M. \& Kinner, Russell H. P.E., Enhancing PLC Performance with Vision Systems. 18th Annual ESD/HMI International Programmable Controllers Conference Proceedings, 1989, p. 387-399

11. Maher, Michael J. I 18th Annual ESD/SMI International Programmable Controllers Conference Proceedings, 1989, p. 431436.

12. Sergin Ozene, "SMPS circuit with multiple AC/DC inputs and application of such circuit to computer power supplies or laptop adapters". United States 2010, May 13,2010, page: 1-8

13. Foutz, Jerrold. "Switching-Mode Power Supply Design Tutorial Introduction". Retrieved 2008-10-06.

14. K. T. Erickson, "Programmable logic controllers," in IEEE Potentials, vol. 15, no. 1, , Feb.-March 1996, pp. 14-17.

15. Kovaliuk, D. O., Huza, K. M., \& Kovaliuk, O. O. "Development of SCADA System based on Web Technologies". International Journal of Information Engineering and Electronic Business (IJIEEB), 2018, page: 25-32.

16. Abbas, H.A. and Mohamed, A.M., "Review in the design of web based SCADA systems based on OPC DA protocol", International Journal of Computer Networks, Vol. 2, No. 6, February 2011, pp.266-277

\section{AUTHORS PROFILE}

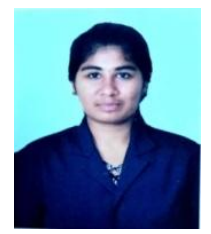

V. Asmitha (16EIR013) is studying final year in the Department of Electronics and Instrumentation Engineering, Kongu Engineering College, Perundurai, Tamil Nadu, India.

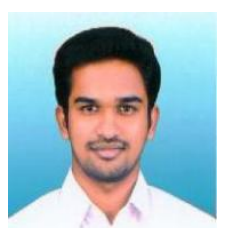

R. Rajkumar is Assistant Professor in the Department of Electronics and Instrumentation Engineering, Kongu Engineering College, Perundurai, Tamil Nadu, India. He obtained his B.E (Electrical) and M.E (Control and Instrumentation Engineering) from Kongu Engineering College, Perundurai and pursuing Ph.D degree at Anna University, Chennai, India. His area of interest includes Power Quality, Renewable Energy Sources, Virtual Instrumentation and Soft computing Techniques.

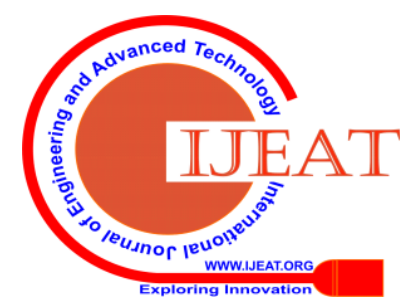




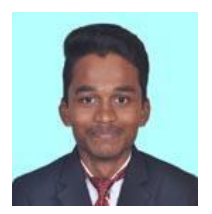

R. Bharath Kumar (16EIR015) is studying final year in the Department of Electronics and Instrumentation Engineering, Kongu Engineering College, Perundurai, Tamil Nadu, India.

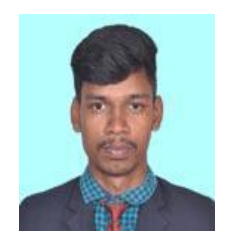

R. Bharathidhasan (16EIR016) is studying final year in the Department of Electronics and Instrumentation Engineering, Kongu Engineering College, Perundurai, Tamil Nadu, India.

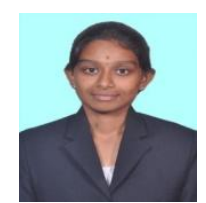

G. Keerthana (16EIL111) is studying final year in the Department of Electronics and Instrumentation Engineering, Kongu Engineering College, Perundurai, Tamil Nadu, India.

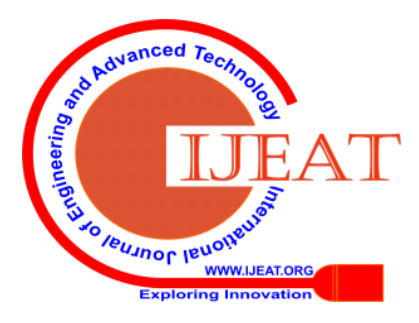

